JURNAL SOSAINS

JURNAL SOSIAL DAN SAINS

VOL 2 NO 22022

P-ISSN 2774-7018, E-ISSN 2774-700X

\title{
IMPLEMENTASI PENDIDIKAN KARAKTER DISIPLIN \\ DALAM MENINGKATKAN HAFALAN AL-QUR'AN SISWA
}

\author{
Aliya Fatmawati ${ }^{1}$ dan Astuti Darmiyanti ${ }^{2}$ \\ ${ }^{1,2}$ Fakultas Magister Pendidikan Agama Islam Universitas Singaperbangsa Karawang, Indonesia \\ Corresponding Author : Aliya Fatmawati ${ }^{1}$ \\ Email : ummuffnn@gmail.com ${ }^{1}$ dan ummuffnn@gmail.com ${ }^{2}$
}

Info Artikel :

Diterima : 03 Februari 2022

Disetujui : 08 Februari 2022

Dipublikasikan : 15 Februari 2022

\begin{abstract}
ABSTRAK
Latar Belakang : Disiplin dalam belajar merupakan suatu kebiasaan yang harus dimiliki setiap orang. Dengan disiplin, seseorang akan mendapat pengetahuan secara luas dan menyeluruh tentang suatu ilmu. Tujuan : Penelitian ini bertujuan untuk mengungkap implementasi Pendidikan karakter disiplin dalam meningkatkan hafalan $\mathrm{Al}$ Qur'an siswa di SMPI Babussalam dengan sub fokus mencakup strategi perencanaan karakter disiplin siswa dan implementasinya dalam meningkatkan hafalan Al Qur'an. Metode : Penelitian ini menggunakan pendekatan kualitatif dengan pengumpulan data, teknik observasi, wawancara dan dokumentasi. Hasil : Hasil penelitian menunjukkan bahwa perencanaan karakter disiplin pada SMPI Babussalam menerapkan pendekatan tauladan, pengawasan dan penyadaran. Kesimpulan : Strategi perencanaan pembentukan karakter disiplin siswa SMPI Babussalam dalam meningkatkan hafalan Al Qur'an, menurut hasil wawancara dengan kepala SMPI Babussalam, untuk mendapatkan hasil yang optimal dalam hafalan siswa diperlukan keteladaanan, bimbingan dan pengawasan.
\end{abstract}

Keywords: Pendidikan Karakter, Disiplin, Siswa

Keywords: Character Education, Discipline, Students

\section{ABSTRACT}

Background : Discipline in learning is a habit that everyone should have. With discipline, a person will gain broad and thorough knowledge about a science. Purpose : This study aims to reveal the implementation of disciplinary character education in improving students' memorization of the Qur'an at SMPI Babussalam with sub-focus covering strategies for planning student discipline characters and their implementation in improving the memorization of the Qur'an, strategies for implementing student discipline characters in improving memorization of the Qur'an. an, the results of the evaluation of the application of the character of discipline in improving memorization. Method : This study uses a qualitative approach with data collection, observation techniques, interviews and documentation. Results : The results of the study indicate that the planning of disciplinary character at SMPI Babussalam applies an exemplary approach, supervision and awareness. Conclusion: The planning strategy for forming the disciplined character of SMPI Babussalam students in improving the memorization of the Qur'an, according to the results of interviews with the head of SMPI Babussalam, to get optimal results in student memorization requires exemplary, guidance and supervision. 


\section{PENDAHULUAN}

Pendidikan karakter saat ini merupakan hal yang sangat urgen dikarenakan banyaknya krisis moral disemua kalangan, baik anak-anak, remaja maupun orang tua (Nudin, 2020). Banyak nilai karakter yang dapat ditanamkan dalam dunia Pendidikan, salah satunya adalah karakter disiplin. Dengan adanya karakter disiplin diharapkan para siswa mampu menumbuhkan karakter-karakter lainnya (Rachmadyanti, 2017). Tidak dipungkiri karakter disiplin membutuhkan pembiasaan dan lingkungan yang mendukung agar tercipta kesadaran bagi para siswa untuk berdisiplin (Octavia \& Sumanto, 2019).

Perilaku disiplin di sekolah sangat dibutuhkan untuk menunjang keberhasilan dalam menuntut ilmu, begittu pula dalam menghafal Al Qur'an (Thobroni, 2013). Menghafal AlQur'an adalah simbol bagi umat Islam dan duri bagi masuknya musuh-musuh Islam. James Mansiz berkata, "Boleh jadi, Al-Qur"an merupakan kitab yang paling banyak dibaca di seluruh dunia. Tanpa diragukan lagi, Al-Qur'an merupakan kitab yang paling mudah dihafal.Al-hafidz as-Suyuti berkata bahwa "pengajaran Al-Qur'an adalah dasar dari prinsip-prinsip Islam (Jaelani, 2020). Anak-anak tumbuh diatas fitrahnya dan cahayacahaya hikmahnya yang masuk dalam kalbu mereka sebelum dikuasai oleh hawa nafsu dan cahaya hitamnya yang dilekati kotoran-kotoran maksiat dan kesesatan" (Fitriyani, 2021).

Orang menghafal Al-Qur'an lebih sukar dilakukan daripada membaca dan memahaminya. Hal ini disebabkan oleh dua faktor yaitu faktor eksternal dan faktor internal (Kamal, 2016). Faktor eksternal adalah Al-Qur'an mempunyai banyak lembaran sehingga menghabiskan banyak waktu, Adapun faktor internal adalah faktor yang berasal dari individu itu sendiri baik jasmani maupun rohani yang menghalangi seseorang untuk menghafal Al-Qur'an.Akan tetapi selama kita terus berusaha menghafal pasti Allah akan memudahkan. Hal yang terpenting dalam menghafal Al-Qur'an adalah bagaimana meningkatkan kelancaran (menjaga) atau melestarikan Al-Qur'an agar tetap ada dalam dada. Oleh karena itu pemeliharaan Al-Qur'an dapat diimplementasikan pada lembagalembaga pendidikan Islam salah satunya melalui program tahfidz Al-Qur'an. Program adalah suatu unit atau kesatuan kegiatan maka program merupakan sebuah sistem, yaitu rangkaian kegiatan yang dilakukan bukan hanya satu kali tetapi berkesinambungan. Pelaksanaan program selalu terjadi dalam satu organisasi yang artinya harus melibatkan sekelompok orang (Silaban \& Yuliani, 2017). Tahfidz Al-Qur'an terdiri dari dua suku kata, yaitu Tahfidz dan Al-Qur'an, yang keduanya memiliki makna yang berbeda. Yaitu tahfidz yang artinya menghafal. Menghafal dari kata dasar hafal yang dalam bahasa arab hafidzayahfadzu-hifdzan artinya yaitu selalu ingat dan sedikit lupa (Fatmawati, 2019).

Pelaksanaan kegiatan tahfidz atau menghafal Al Qur'an kebanyakan praktisi pendidikan memang condong kepada dimensi pengetahuan, yang memegang pendapat bahwa jika aspek kognitif telah dikembangkan secara benar, maka aspek afektif akan ikut berkembang secara positif, namun realitanya aspek afektif dan psikomotorik pun sangat berperan (Afiyah, 2019). Salah satu aspek afektif yang memiliki peranan penting adalah disiplin dalam hal pembelajaran. Siswa yang memiliki disiplin belajar yang baik akan mempunyai kecakapan mengenai belajar yang baik. Hal ini sangat diperlukan untuk. meningkatkan prestasi belajar siswa, berhasil tidaknya siswa dalam pembelajarannya dilihat dari bagaimana ia mendisiplinkan dirinya untuk belajar dengan baik. Djamarah juga menyatakan bahwa agar siswa lebih maju, siswa harus disiplin di dalam belajar baik di sekolah, di rumah maupun di perpustakaan. Disiplin belajar akan membuat seseorang memiliki kecakapan mengenai cara belajar yang baik dan pembentukan watak yang baik pula (Rohman, 2018). Cara belajar yang baik adalah suatu kecakapan yang dapat dimiliki 
oleh setiap orang dengan jalan latihan. Keteraturan dan disiplin harus dikembangkan dengan penuh kemauan dan kesungguhan.

Pondok pesantren Babussalam Kota Depok pada jenjang tingkat SMP Islam merupakan salah satu pondok pesantren yang menerapkan karakter disiplin sebagai salah satu penunjang untuk mencapai tujuan lembaga itu sendiri yaitu dapat menghafalkan Al Qur'an. Diantara banyaknya program yang dicanangkan terdapat program setoran hafalan Al Qur'an dan muraja'ah yang dilakukan sebanyak empat kali dalam sehari semalam. Hal tersebut dibutuhkan kedisiplinan dalam menjalaninya sehingga SMPI Babussalam memberikan penghargaan atau reward bagi yang berhasil dan sanksi atau punishment bagi yang melanggar peraturan tersebut sebagai upaya peningkatan hafalan para siswa. Penelitian ini bertujuan untuk mengungkap implementasi Pendidikan karakter disiplin dalam meningkatkan hafalan Al Qur'an siswa di SMPI Babussalam dengan sub fokus mencakup stategi perencanaan karakter disiplin siswa dan implementasinya dalam meningkatkan hafalan Al Qur'an.

\section{METODE PENELITIAN}

Jenis data Penelitian ini termasuk penelitian kualitatif yaitu penelitian yang menghasilkan data-data deskriptif berupa kata-kata tertulis atau lisan dari orang-orang ataupun perilaku yang dapat diamati. Sumber data yang digunakan oleh penulis dalam kegiatan penelitian adalah sebagai berikut: data primer yaitu data yang diperoleh dari sumber datanya secara langsung sedangkan data sekunder yaitu data yang didapatkan daru studi - studi sebelumnya. Data sekunder dapat diperoleh dari berbagai sumber seperti jurnal, laporan, buku dan lain - lain. Fokus penelitian ini dibatasi pada Implementasi Pendidikan Karakter Disiplin Dalam Meningkatkan Hafalan Al Qur'an Siswa Di SMP Islam Pondok Pesantren Babussalam Depok. Subyek penelitian ini adalah siswa kelas IX SMP Islam Pondok Pesantren Babussalam Depok .Informan dalam penelitian ini adalah Kepala Sekolah, Guru Mata Tahfidz dan siswa kelas IX.

\section{HASIL DAN PEMBAHASAN}

\section{A. Pengertian kedisiplinan}

Disiplin berasal dari kata latin, discipulus, yang berarti siswa atau murid. Kata ini mengalami perubahan bentuk dan perluasan arti, antara lain berarti ketaatan, metode pengajaran, mata pengajaran dan perlakuan yang cocok bagi seorang murid. Sehubungan dengan definisi tersebut kata ini juga berarti latihan yang membetulkan serta kontrol yang memperkuat ketaatan.

Dalam Kamus Besar Bahasa Indonesia, disiplin adalah tata tertib di sekolah, kemiliteran, dan lain sebagainya (ketaatan/kepatuhan terhadap tata tertib di sekolah). Sedangkan pola asuh berarti bentuk atau sistem dalam menjaga, merawat dan mendidik. Jika ditinjau dari terminologi, pola asuh anak adalah suatu pola atau sistem yang diterapkan dalam menjaga, merawat dan mendidik seorang anak yang bersifat relatif konsisten dari waktu ke waktu. Pola perilaku ini dapat dirasakan oleh anak dari segi negatif atau positif.

Macam-macam Disiplin menurut Unaradjan bahwa faktor-faktor yang mem pengaruhi pembinaan dan pembentukan disiplin diri ada dua yaitu faktor ekstern, Antara lain keadaan keluarga yang merupakan tempat utama Pembinaan disiplin yang sangat penting, keadaan sekolah yang dimaksudkan adalah ada tidaknya sarana-sarana yang diperlukan bagi kelancaran proses belajar mengajar disekolah seperti aspek pada guru mempengaruhi disiplin diri disekolah, keadaan masyarakat yang turut menentukan berhasil tidaknya pembinaan dan pendidikan disiplin diri. Faktor intern yaitu keadaan fisik yang 
sangat mempengaruhi seseorang dalam menerapkan disiplin, keadaan psikis karena hanya orang-orang yang sehat secara psikis dapat menghayati norma-norma yang ada dalam masyarakat dan keluarga. Hal-hal pokok dalam menanamkan perilaku disiplin, ada empat hal penting yang harus dipertimbangkan dalam mendisiplinkan anak :

a. Aturan-aturan (rules)

Aturan digambarkan sebagai pola berperilaku di rumah, di sekolah ataupun di masyarakat. Aturan-aturan itu memiliki nilai pendidikan dan membantu anak untuk menahan perilaku yang tidak diinginkan oleh masyarakat.

b. Hukuman (Punishment)

Beberapa fungsi hukuman dalam menanamkan disiplin adalah sebagai berikut:

a) Yang bersifat membatasi

Hukuman akan menghalangi pengulangan perilaku yang tidak diinginkan oleh masyarakat.

b) Yang bersifat mendidik

Anak-anak belajar tentang hal baik dan buruk melalui pemberian atau tidak diberikannya hukuman ketika mereka bertindak tidak sesuai dengan standar sosial yang berlaku.

c) Sebagai pembangkit motivasi untuk menghindari perilaku yang ditolak masyarakat.

c. Imbalan (Reward)

Imbalan merupakan suatu pengahragaan untuk hasil baik yang telah dicapai. Imbalan tidak harus berbentuk materi, tetapi bisa juga dalam bentuk kata-kata yang menyenangkan (pujian), sentuman, tepukan dan belaian (Ardhoyo, 2015).

\section{B. Menghafal Al Qur'an}

Al- Qur'ān merupakan kitab Allah yang di dalamnya berisi petunjuk bagi umat manusia (Husni, 2019). Sebagai seorang muslim, kita di perintahkan untuk membaca, menghafal, serta mengaplikasikannya dalam kehidupan sehari - hari. Dalam hal ini, Allah telah berfirman dalam QS.Al Qamar ayat 17

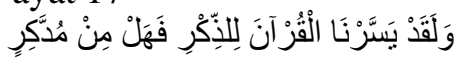

Artinya : Dan sesungguhnya telah Kami mudahkan Al-Quran untuk pelajaran, maka adakah orang yang mengambil pelajaran.

Menurut tafsir As Sa'di Syaikh Abdurrahman bin Nashir as-Sa'di, pakar tafsir abad $14 \mathrm{H}$ : "Dan sungguh telah Kami mudahkan al-Quran untuk pelajaran, maka adakah orang yang mengambil pelajaran?" artinya, Kami mudahkan kata-kata al-Quran untuk dihafal dan dijelaskan untuk dipahami dan diketahui, karena al-Quran adalah kata-kata terbaik, maknanya paling benar dan penjelasannya paling gamblang. Siapa saja yang mempelajarinya, maka akan diberi kemudahan oleh Allah untuk mencapai maksudnya secara amat mudah. Al-Quran adalah peringatan menyeluruh untuk semua hal yang perlu diingat oleh seluruh alam, berupa halal, haram, berbagai hukum, perintah, larangan, hukum balasan, nasihat, pelajaran, akidah yang bermanfaat dan berita-berita benar, serta paling luhur secara mutlak. Al-Quran adalah ilmu yang bermanfaat jika dicari oleh seseorang, akan diberi pertolongan. Sebagian ulama -Salaf mengatakan tentang ayat ini, "Tidaklah orang menuntut ilmu, melainkan pasti ditolong." Karena itu Allah menyeru hambahambaNya untuk mengarah padaNya dan mengingat FirmanNya, "Maka adakah yang mau mengambil pelajaran".

Adapun Keutamaan menghafal Al Qur'an :

1. Penghafal Qur'an adalah Shahibul Qur'an 
Syaikh Muhammad Nashiruddin Al Albani menyatakan, "ketahuilah, makna dari shahibul Qur'an adalah orang yang menghafalkannya di hati. berdasarkan sabda nabi Shallallahu'alaihi Wasallam :

$$
\text { يؤم القوم أقرؤهم لكتاب الله }
$$

"hendaknya yang mengimami sebuah kaum adalah yang paling aqra' terhadap kitabullah"

Maksudnya yang paling hafal. Maka derajat surga yang didapatkan seseorang itu tergantung pada banyak hafalan Al Qur'annya di dunia, bukan pada banyak bacaannya, sebagaimana disangka oleh sebagian orang. Maka di sini kita ketahui keutamaan yang besar bagi pada penghafal Al Qur'an. Namun dengan syarat ia menghafalkan Al Qur'an untuk mengharap wajah Allah tabaaraka wa ta'ala, bukan untuk tujuan dunia atau harta" (Silsilah Ash Shahihah, 5/281).

2. Al Qur'an akan menjadi syafa'at bagi shahibul Qur'an

Rasulullah Shallallahu'alaihi Wasallam bersabda:

$$
\text { اقر أوا القرآن فإنه يأتي يوم القيامة شفيعا لأصحابه }
$$

"bacalah Al Qur'an, karena ia akan datang pada hari kiamat sebagai syafa'at bagi shahibul Qur'an" (HR. Muslim 804)

3. Derajat di surga tergantung pada hafalan Qur'an

Semakin banyak hafalannya, akan semakin tinggi kedudukan yang didapatkan di surga kelak. Rasulullah Shallallahu'alaihi Wasallam bersabda :

$$
\text { يقال لصاحب القرآن اقرأ وارتقي، ورتل كما كنت ترتل في الدنيا، فإن منزللك عند آخر آية تقرؤها }
$$

"akan dikatakan kepada shahibul qur'an (di akhirat) : bacalah dan naiklah, bacalah dengan tartil sebagaimana engkau membaca dengan tartil di dunia. karena kedudukanmu tergantung pada ayat terakhir yang engkau baca" (HR. Abu Daud 2240, dishahihkan Al Albani dalam Shahih Abi Daud).

4. Termasuk sebaik-baik manusia

Rasulullah Shallallahu'alaihi Wasallam bersabda:

$$
\text { خيركم من تعلم القرآن و علَّمه }
$$

"sebaik-baik kalian adalah yang mempelajari Al Qur'an dan mengajarkannya" (HR. Al Bukhari 4639).

5. Allah mengangkat derajat shahibul Qur'an di dunia

Rasulullah Shallallahu'alaihi Wasallam bersabda :

$$
\text { إن الله يرفع بهذا الكتاب أقو اماً ويضع به آخرين }
$$




\section{Implementasi Pendidikan Karakter Disiplin dalam Meningkatkan Hafalan Al-Qur'an Siswa}

"sesungguhnya Allah mengangkat beberapa kaum dengan Al Qur'an ini dan menghinakan yang lain dengannya" (HR. Muslim 817)

6. Penghafal Al Qur'an lebih diutamakan untuk menjadi imam

Rasulullah Shallallahu'alaihi Wasallam bersabda:

$$
\text { يؤم القوم أقرؤهم لكتاب الله }
$$

"hendaknya yang mengimami sebuah kaum adalah yang paling aqra' terhadap kitabullah" (HR. Abu Daud 582, dishahihkan Al Albani dalam Shahih Abi Daud)

Selain keutamaan-keutamaan di atas, ada beberapa hal juga yang menjadi pendorong untuk kita semua agar menghafalkan Al Qur'an:

1. Meneladani Nabi Shallallahu'alaihi Wasallam

Panutan kita, Rasulullah Shallallahu'alaihi Wasallam menghafalkan Al Qur'an, dan setiap bulan Ramadhan Jibril datang kepada beliau untuk mengecek hafalan beliau. Hal ini diceritakan oleh Ibnu Abbas radhiallahu'anhuma:

كان رسول الله صلى الله عليه وسلم أجود الناس ، وكان أجود ما يكون في رمضان حين يلقاه جبريل ، وكان يلقاه في

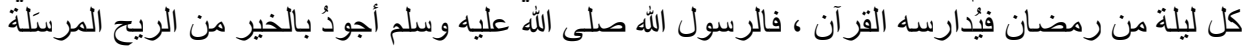

"Rasulullah shallallahu 'alaihi wa sallam adalah orang yang paling dermawan. Dan beliau lebih dermawan lagi di bulan Ramadhan saat beliau bertemu Jibril. Jibril menemuinya setiap malam untuk mengajarkan Al Qur'an. Dan kedermawanan Rasulullah shallallahu 'alaihi wa sallam melebihi angin yang berhembus" (HR. Bukhari, no.6)

2. Membaca Al Qur'an adalah ibadah yang agung

Membaca Al Qur'an adalah ibadah, setiap satu huruf diganjar satu pahala.

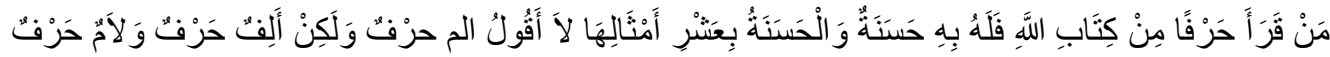

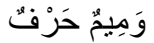

"barangsiapa yang membaca 1 huruf dari Al Qur'an, maka baginya 1 kebaikan. dan 1 kebaikan dilipat-gandakan 10x lipat. aku tidak mengatakan alif lam miim itu satu huruf, tapi alim satu huruf, lam satu huruf dan mim satu huruf" (HR. At Tirmidzi 2910, ia berkata: "hasan shahih gharib dari jalan ini")

Dan banyak lagi keutamaan dari membaca Al Qur'an. Maka seorang Muslim yang hafal Al Qur'an dapat dengan mudahnya membaca kapan saja dimana saja, langsung dari hafalannya tanpa harus membacanya dari mushaf. Dan ini merupakan ibadah yang agung. Ibnu Mas'ud berkata:

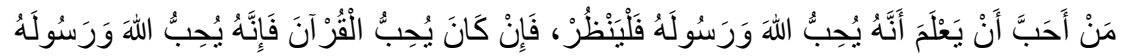

"Barangsiapa yang ingin mengetahui bahwa dia mencintai Allah dan Rasul-Nya, maka perhatikanlah, jika ia mencintai Al Quran maka ia mencintai Allah dan Rasul-Nya" (HR. Al Baihaqi dalam Syu'abul Iman, Al Haitsami dalam Majma Az Zawaid berkata: "semua rijalnya shahih"). 
3. Modal utama dalam mempelajari agama

Al Qur'an adalah sumber hukum dalam Islam. Dengan menghafalkan Al Qur'an, seseorang lebih mudah dalam mempelajari ilmu agama (Ginanjar, 2017). Permasalahan dapat mengeluarkan ayat-ayat yang menjadi dalil terhadap masalah tersebut langsung dari hafalannya. Yang kemudian ia perjelas lagi dengan penjelasan para ulama mengenai ayat tersebut. Ibnu 'Abdl Barr mengatakan:

$$
\text { طلب العلم درجات ورتب لا ينبغي تعديها، ومن تعدابها جملة فقد تعدى سبيل السلف رحمهم الله، فأول العلم حفظ }
$$

"Menuntut ilmu itu ada tahapan dan tingkatan yang harus dilalui, barangsiapa yang melaluinya maka ia telah menempuh jalan salaf rahimahumullah. Dan ilmu yang paling pertama adalah menghafal kitabullah "azza wa jalla dan memahaminya" (dinukil dari Limaadza Nahfadzul Qur'an, Syaikh Shalih Al Munajjid).

\section{Modal utama dalam berdakwah}

Kata para ulama, hidayah ada 2 macam: hidayah taufiq yang ada di tangan Allah dan hidayah al irsyad wal bayan yaitu dakwah yang menjadi tugas para Nabi dan Rasul dan juga kita. Dan Al Qur'an adalah sumber dari hidayah ini, Allah Ta'ala berfirman:

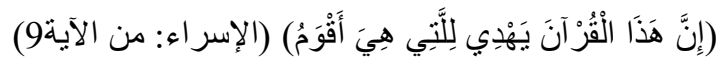

"Sesungguhnya Al Quran ini memberikan hidayah kepada (jalan) yang lebih lurus" (QS. Al Isra: 9)

\section{Menjaga keotentikan Al Qur'an}

Salah satu keistimewaan Al Qur'an adalah keotentikannya terjaga, tidak sebagaimana kitab-kitab samawi yang lain (Khalid, 2017). Salah satu sebab terjaganya hal tersebut adalah banyak kaum Muslimin yang menghafalkan Al Qur'an di dalam dada-dada mereka. Sehingga tidak mudah bagi para penyeru kesesatan dan musuh-musuh Islam untuk menyelipkan pemikiran mereka lewat Al Qur'an atau mengubahnya untuk menyesatkan umat Islam.

\section{Tadabbur dan Tafakkur}

Dengan menghafal Al Qur'an, seseorang bisa lebih mudah dan lebih sering bertadabbur dan ber-tafakkur. Yaitu merenungkan isi Al Qur'an untuk mengoreksi keadaan dirinya apakah sudah sesuai dengannya ataukan belum dan juga memikirkan tanda-tanda kebesaran Allah. Allah Ta'ala berfirman :

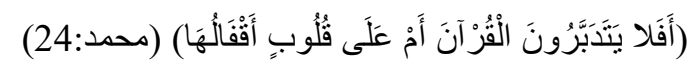

"Maka apakah mereka tidak men-tadabburi Al Quran ataukah hati mereka terkunci?" (QS. Muhammad: 24).

7. Mengobati

Al Qur'an adalah obat bagi penyakit hati dan penyakit jasmani. Allah Ta'ala berfirman

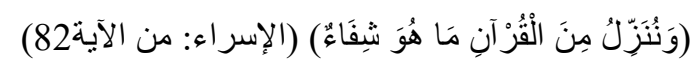




\section{Implementasi Pendidikan Karakter Disiplin dalam Meningkatkan Hafalan Al-Qur'an Siswa}

“Dan Kami turunkan dari Al Quran suatu yang menjadi penawar" (QS. Al Isra: 82).

\section{KESIMPULAN}

Berdasarkan hasil penelitian di lapangan dan analisis hasil penelitian tentang Implementasi Pendidikan Karakter Disiplin Dalam Meningkatkan Hafalan Al Qur'an Siswa Di SMP Islam Pondok Pesantren Babussalam Depok dapat penulis tarik kesimpulan Strategi perencanaan pembentukan karakter disiplin siswa SMPI Babussalam dalam meningkatkan hafalan Al Qur'an, menurut hasil wawancara dengan kepala SMPI Babussalam, untuk mendapatkan hasil yang optimal dalam hafalan siswa diperlukan keteladaanan, bimbingan dan pengawasan. Strategi pelaksanaan pembentukan karakter disiplin siswa SMPI Babussalam dalam meningkatkan hafalan Al Qur'an.

Waktu yang digunakan untuk setoran hafalan dan muraja'ah di SMPI Babussalam terbagi menjadi 4 yaitu : dhuha, zhuhur, ashar dan subuh isya (tilawah). Adapun ketentuan jumlah hafalan juga diwajibkan untuk disiplin dan jumlahnya variatif yang harus disetorkan masing-masing kelas berbeda, dengan disiplin dalam mengikuti waktu pembelajaran Tahfidz dan ketentuan jumlah minimal yang disetorkan membuat para siswa kelas IX memiliki jumlah hafalan yang membanggakan. Berdasarkan data yang didapat dari Koordinator Tahfidz SMPI Babussalam tingkat kesuksesan tercapainya target untuk 9A $65 \%$ dan 9B $97 \%$.

\section{REFERENCES}

Afiyah, Sulfa. (2019). implementasi program tahfidz dalam memperkuat karakter siswa di mts negeri 3 ponorogo. Ponorogo: IAIN Ponorogo.

Ardhoyo, T. E. (2015). Mengelola Komunikasi. WACANA: Jurnal Ilmiah Ilmu Komunikasi, 14(1), 18-44.

Fatmawati, Eva. (2019). Manajemen Pembelajaran Tahfidz Al-Qur'an. Jurnal Isema: Islamic Educational Management, 4(1), 25-38.

Fitriyani, Nur. (2021). Tanggapan siswa terhadap peran pembimbing hubungannya dengan aktivitas siswa menghafal Al-Qur'an: Penelitian di Nurul Iman Boarding School, Cigalontang, Singaparna, Tasik. Bandung: Uin sunan gunung djati bandung.

Ginanjar, Muhammad Hidayat. (2017). Aktivitas Menghafal Al-Qur'an Dan Pengaruhnya Terhadap Prestasi Akademik Mahasiswa (Studi Kasus Pada Mahasiswa Program Beasiswa Di Ma'had Huda Islami, Tamansari Bogor). Edukasi Islami: Jurnal Pendidikan Islam, 6(11), 20.

Husni, Muhammad. (2019). Studi Al-Qur'an: Teori Al Makkiyah dan Al Madaniyah. AL-IBRAH, 4(2), 68-84.

Jaelani, Ahmad. (2020). Efektivitas Program Tahfidz Al-Qur'an dalam Memperkuat Karakter Disiplin Belajar Siswa Madrasah Tsanawiyah (MTs) Al-Hidayah GUPPI Kota Cirebon. Al-Tarbawi Al-Haditsah: Jurnal Pendidikan Agama Islam, 6(2), 1-15.

Kamal, Mustafa. (2016). Pengaruh Pelaksanaan Progam Menghafal Al Qur'an Terhadap Prestasi Belajar Siswa:(Studi Kasus Di MA Sunan Giri Wonosari Tegal Semampir Surabaya). Surabaya: Universitas Muhammadiyah Surabaya. Khalid, Idham. (2017). Alquran Kalamullah Mukjizat Terbesar Rasulullah SAW. Diya Al-Afkar: Jurnal Studi Al-Quran Dan Al-Hadis, 5(01), 39-74. 
Nudin, Burhan. (2020). Konsep Pendidikan Islam Pada Remaja di Era Disrupsi Dalam Mengatasi Krisis Moral. LITERASI (Jurnal Ilmu Pendidikan), 11(1), 63-74.

Octavia, Erna, \& Sumanto, Ines. (2019). Peran guru Pendidikan Kewarganegaraan dalam membentuk karakter disiplin siswa di sekolah. Jurnal Pendidikan Kewarganegaraan, 2(2).

Rachmadyanti, Putri. (2017). Penguatan pendidikan karakter bagi siswa sekolah dasar melalui kearifan lokal. JPsd (Jurnal Pendidikan Sekolah Dasar), 3(2), 201-214.

Rohman, Fatkhur. (2018). Peran Pendidik Dalam Pembinaan Disiplin Siswa di Sekolah/Madrasah. Ihya Al-Arabiyah: Jurnal Pendidikan Bahasa Dan Sastra Arab, 4(1).

Silaban, Susi J., \& Yuliani, Febri. (2017). Implementasi Program Adiwiyata (Studi pada SMP Negeri 20 Pekanbaru). Riau: Riau University.

Thobroni, Ahmad Yusam. (2013). Etika Pelajar dalam Perspektif Ibn Jama'ah. Jurnal Pendidikan Agama Islam (Journal of Islamic Education Studies), 1(2), 303-318.

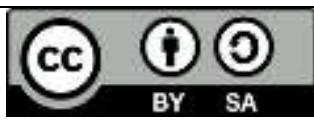

This work is licensed under a Creative Commons Attribution-ShareAlike 4.0 International License. 